\title{
Glanzmann Thrombasthenia in a Korean Patient: A Postoperative Intracranial Hemorrhagic Diasthesis in a Patient with a Rupture of a Cerebral Aneurysm
}

\author{
Mi Sun Choi, MD, Joo Hee Lee, RN, Yong Cheol Lim, MD \\ Department of Neurosurgery, Ajou University School of Medicine, Suwon, Korea
}

Background: Glanzmann thrombasthenia (GT) is a rare disease with severe insufficiency of platelet function. There are no reports of GT associated with a cerebral hemorrhage.

Case report: A 45-year-old woman had a stuporous mentality. Her computed tomographic (CT) angiography revealed a rupture of the posterior cerebral artery aneurysm. Hunt-Hess grade was 4 points and Fisher grade was 3 points. A clipping of the aneurysm was performed and proceeded to external ventricular drainage for hydrocephalus after 6 days. But, a new hemorrhage was detected several times via a follow-up brain CT. Various blood tests were conducted to evaluate the bleeding tendency, and the GT was diagnosed with PFA-200. The ventriculoperitoneal shunt was performed after the platelets transfusion, and she was discharged without other complications.

Conclusion: With nonspecific and recurrent intracranial hemorrhage, a GT should be included in the differential diagnosis, which is important in controlling bleeding during the surgery.

J Neurocrit Care 2017;10(2):126-128

Key words: Trombasthenia; Postoperative hemorrhages; Aneurysm, Ruptured

\author{
Received October 15, 2017 \\ Revised December 3, 2017 \\ Accepted December 6, 2017 \\ Corresponding Author: \\ Yong Cheol Lim, MD \\ Department of Neurosurgery, Ajou \\ University School of Medicine, 164 \\ World cup-ro, Yeongtong-gu, Suwon \\ 16499, Korea \\ Tel: +82-31-219-5230 \\ Fax: +82-31-219-5238 \\ E-mail : nsyclim@gmail.com
}

Copyright $\odot 2017$ The Korean Neurocritical Care Society

\section{INTRODUCTION}

Glanzmann thrombasthenia (GT) is a very rare and severe insufficiency of platelet function caused by an inherited deficiency or dysfunction of the glycoprotein IIb/IIla complex and the platelet fibrinogen receptor. ${ }^{1}$ Patients with GT have a tendency to develop spontaneous or post-traumatic bleeding. In GT patients, the operation itself is dangerous, and the risk of cerebral hemorrhage is considerably increased because of secondary brain damage.

\section{CASE REPORT}

A 45-year-old woman with a stuporous mentality visited the emergency department. She was unconscious, and it was hard to identify her medical history or family history. A brain computed tomographic (CT) angiography revealed

cc This is an Open Access article distributed under the terms of the Creative Commons Attribution Non-Commercial License (http://creativecommons.org/licenses/bync/4.0) which permits unrestricted non-commercial use, distribution, and reproduction in any medium, provided the original work is properly cited. 

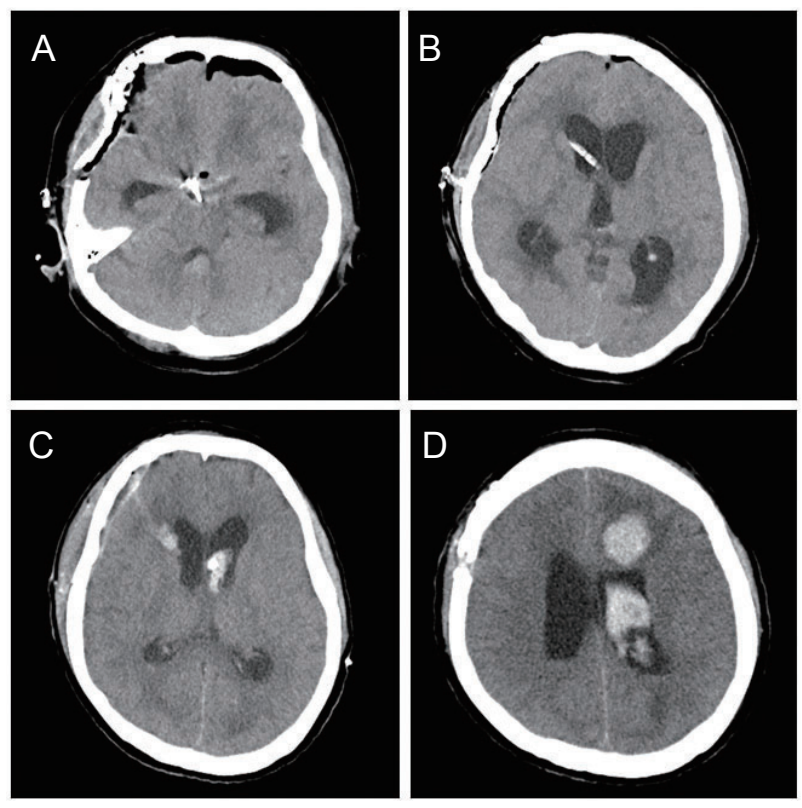

Figure 1. Brain computed tomography finding shows the status of the clipping of an aneurysm and inserting an intraoperative external ventricular drainage catheter (A, B). A new hemorrhage was observed at the removal site of the existing catheter in the right side and at the insertion site of the new catheter in the left side $(C)$. The expansion of the hemorrhage around catheter in the left side was detected (D).

a rupture of the posterior cerebral artery aneurysm. At the time of admission, her Hunt-Hess grade was 4 points and her Fisher grade was 3 points.

A clipping of the aneurysm was performed simultaneously with an insertion of a intraoperative external ventricular drainage (EVD) catheter for hydrocephalus (Fig. 1). After 7 days of the clip operation, a change of EVD catheter was performed, and a new intracranial hemorrhage was observed in each of the removal sites of the existing catheter in the right side and an insertion site of the new catheter in the left side (Fig. 1). An intracranial hemorrhage located along the EVD catheter identified by a CT scan was due to an iatrogenic injury during the procedure, not a rebleeding of the clipped aneurysm. In addition, the bleeding continued at the surgical wound of the scalp.

Various blood tests were conducted to evaluate the bleeding tendency, and most of the laboratory test results, including a coagulation factor assay and her Von Willebrand factor were normal. The hemoglobin was $13.5 \mathrm{~g} /$
$\mathrm{dL}$, hematocrit was $40 \%$, platelet count was $288 \times 10^{3} /$ $\mu \mathrm{L}$, prothrombin time was 10.8 seconds, and activated partial thromboplastin time was 29 seconds. Additional tests were performed to determine the cause of the bleeding. A Platelet Function Analyzer-200 (PFA-200; Siemens, Munich, Germany) using a collagen+epinephrine embeded cartridges resulted in more than 254 seconds (normal range 81-192 seconds). The results of PFA-200 using a collagen+adenosine diphosphate embeded cartridges were prolonged to 210 seconds (normal range 61-116 seconds). Glanzmann thrombasthenia was confirmed by these blood test results, and also by the consulting of a hematologist. On the 25th postoperative day, she received a platelets transfusions for a ventriculoperitoneal shunt in close cooperation with an anesthesiologist and hematologist. After 50 days of hospitalization, she was discharged with a modified Rankin Scale score of 3 points and the Korean vision of Mini-Mental State Examination of 18 points. Due to her poor family relationships and cognitive function status, her past history could not be determined precisely. At the time of discharge, her caregiver was educated about how the bleeding of a minor injury may be able to be controlled by pressure or by taking a anti-fibrinolytic medicine.

\section{DISCUSSION}

Eduard Glanzmann was a Swiss pediatrician who first discovered the condition of thrombasthenia in $1918 .^{2}$ Platelets are a principal constituent of many restorative physiological procedures, including hemostasis. ${ }^{3}$ Acquired platelet diseases are more likely to be faced in clinical practice than their inherited counterparts, and often emerge as an effect from the onset of medications or underlying medical conditions. In contrast, inherited platelet disorders are rare, and until recently, have been under less scrutiny. ${ }^{3}$

Bleeding events are variable among patients with Glanzmann's thrombasthenia, and menorrhagia, epistaxis, and gingival bleeding are more frequent. ${ }^{4}$ In a study by George et al. ${ }^{5}$ on 113 patients in 1990, the less common Glanzmann's thrombasthenia symptoms were gastroin- 
testinal bleeding (12\%), hematuria (6\%) and intracranial hemorrhage (ICH) (2\%). Also, Toogeh et al. ${ }^{6}$ in 2004, had reported that the most common clinical manifestation was epistaxis (49.7\%) and central nervous system bleeding only occurred in one person $(0.3 \%)$ of 382 patients with GT in Iran.

As it is known, congenital bleeding disorders are a rare manifestation but the leading cause of $\mathrm{ICH}$, which has a high rate of morbidity and mortality. ${ }^{7}$ There are two cases of in-utero death caused by intracranial hemorrhage, one at 24 weeks and the other at 31 weeks of gestation. ${ }^{8}$ George et al. ${ }^{5}$ reported two Paris patients in his review article. One patient had a meningeal hemorrhage after a head trauma at 4 years old, but less severe bleeding. The other patient had an intracerebral hematoma that required surgical evacuation after a fall at age 6 , but the patient recovered well after surgery. The prevalence of $\mathrm{ICH}$ in Glanzmann's thrombasthenia patients is extremely uncommon, but powerful enough to cause death.,

Patients with GT do not require treatment on a regular basis, but will always need therapy during surgical procedures or a bleeding control after an injury. ${ }^{10}$ Antifibrinolytic agents such as tranexamic acid may control the bleeding for mild to moderate events, but platelet transfusions as an alternative method must be considered when clinicians fail to control the bleeding. ${ }^{3}$ Also, patients with GT should require registration with a 24-hour center capable of dealing with this kind of treatment. $3,11,12$

If nonspecific and recurrent intracranial hemorrhage persists, GT should be included in the differential diagnosis, which is important in controlling and treating bleeding during the surgical procedures.

\section{REFERENCES}

1. Toygar HU, Guzeldemir E. Excessive gingival bleeding in two patients with Glanzmann thrombasthenia. / Periodontol 2007;78:1154-8.

2. Nurden AT, Pillois X, Wilcox DA. Glanzmann thrombasthenia: state of the art and future directions. Semin Thromb Hemost 2013;39:642-55.

3. Solh T, Botsford A, Solh M. Glanzmann's thrombasthenia: pathogenesis, diagnosis, and current and emerging treatment options. J Blood Med 2015;6:219-27.

4. Franchini M, Lippi G. NovoSeven (recombinant factor VIla) for the treatment of bleeding episodes and perioperative management in patients with Glanzmann's thrombasthenia. Expert Rev Hematol 2014;7:733-40.

5. George JN, Caen JP, Nurden AT. Glanzmann's thrombasthenia: the spectrum of clinical disease. Blood 1990;75:1383-95.

6. Toogeh G, Sharifian R, Lak M, Safaee R, Artoni A, Peyvandi F. Presentation and pattern of symptoms in 382 patients with Glanzmann thrombasthenia in Iran. Am / Hematol 2004;77:198-9.

7. Tabibian S, Motlagh H, Naderi M, Dorgalaleh A. Intracranial hemorrhage in congenital bleeding disorders. Blood Coagul Fibrinolysis 2017. [Epub ahead of print]

8. Yougbaré I, Lang S, Yang H, Chen P, Zhao X, Tai WS, et al. Maternal anti-platelet $\beta 3$ integrins impair angiogenesis and cause intracranial hemorrhage. / Clin Invest 2015;125:154556.

9. Iqbal I, Farhan S, Ahmed N. Glanzmann thrombasthenia: a clinicopathological profile. / Coll Physicians Surg Pak 2016;26:647-50.

10. Segna E, Artoni A, Sacco R, Giannì AB. Oral surgery in patients with Glanzmann thrombasthenia: a case series. / Oral Maxillofac Surg 2017;75:256-9.

11. Nurden AT, Fiore M, Nurden P, Pillois X. Glanzmann thrombasthenia: a review of ITGA2B and ITGB3 defects with emphasis on variants, phenotypic variability, and mouse models. Blood 2011;118:5996-6005.

12. Fiore M, Nurden AT, Nurden P, Seligsohn U. Clinical utility gene card for: Glanzmann thrombasthenia. Eur J Hum Genet 2012;20. 